\title{
A FORMAÇÃO DO PROFISSIONAL ENFERMEIRO, NO CONTEXTO DAS REFORMAS DE ENSINO NO BRASIL
}

\author{
Maria Cecília Marins de Oliveira* \\ Tatiana De Lurdes Lima** \\ Victor Hugo Baluta***
}

\begin{abstract}
Resumo
O presente estudo procurou observar a trajetória da educação do profissional enfermeiro no período que compreendeu a inauguração da primeira escola de enfermagem no Brasil, em 1890, até o final do século XX. O objetivo foi trazer à discussão a realidade da formação do enfermeiro, tendo por base as legislações regulamentadoras, bem como as Leis de Diretrizes e Bases da Educação Nacional (LDBEN) de 1968 e 1996, que determinaram os encaminhamentos e a institucionalização da profissão. Os aspectos sociais e econômicos foram relevantes, uma vez que caracterizaram momentos políticos que tiveram repercussão no andamento das políticas públicas do profissional de enfermagem. A metodologia contou com o levantamento de obras, buscando conhecer o pensamento e as reflexões dos autores, tendo por base as legislações que contribuem na trajetória dessa formação à luz dos condicionantes legais. A abordagem teórica respaldou-se em autores, como Luiz Antônio da Cunha, Gaudêncio Frigotto, Telma Geovanini, Emerson Elias Merhy, entre outros, que abordam questões sobre a enfermagem e as políticas empreendidas pelos governos, tendo em vista a correlação entre as medidas higiênico/sanitárias, a criação e o desenvolvimento da formação do enfermeiro, no Brasil. Observou-se as contradições sociais que permearam a realidade desse profissional e a relevância econômica determinante das políticas de reforma e desenvolvimento que caracterizaram o caráter racional e centralizador da gestão pública no regime militar, gerando a fragmentaridade dessa categoria profissional. A LDBEN de 1996, todavia, trouxe à discussão a formação do enfermeiro, atendendo expectativas do neoliberalismo e da globalização do mercado.
\end{abstract}

Palavras-chave: Formação profissional do enfermeiro. Educação em Enfermagem. Graduação em Enfermagem. Legislação sobre o Curso de Enfermagem.

\footnotetext{
* Doutora em Educação/FEUSP, Mestre em História do Brasil/UFPR. Professora dos Cursos de Pedagogia, Direito e Enfermagem. Coordenadora do Grupo de Pesquisa dos Cursos de Pedagogia e Direito, da Faculdade Cenecista de Campo Largo/FACECLA, Paraná.

** Pedagoga do Curso de Pedagogia, da Faculdade Cenecista de Campo Largo, Paraná. Mestranda do Programa de Pós-Graduação em Educação da UFPR. Integrante do Grupo de Pesquisa do Curso de Pedagogia da Faculdade Cenecista de Campo Largo, FACECLA, Paraná.

*** Bacharel em Direito, pela Faculdade Cenecista de Campo Largo, Paraná. Curso de Extensão pela Escola Diaconal São Felipe da Mitra de Curitiba. Santuário Nossa Senhora de Lourdes. Campo Comprido, Paraná. Integrante do Grupo de Pesquisa do Curso de Direito da Faculdade Cenecista de Campo Largo, Paraná.
} 


\section{Introdução}

O estudo sobre a formação do profissional enfermeiro, no contexto da educação brasileira, teve como pressuposto o desenvolvimento do processo educativo, inserido na realidade social do profissional, tornando a educação mediadora entre o gesto cultural e o gesto comunicativo que o homem executa. Assim, à medida que a "[...] formação ocorre pelo processo educativo, processa-se também uma transformação" pelos mecanismos teóricos e práticos da própria formação, afirma Romanelli (1986, p. 23).

A temática sobre a formação do enfermeiro tem como referência as reformas educacionais que regulamentaram o encaminhamento das ações educativas desde a criação da primeira escola de enfermagem, no Brasil, em 1890, até o final do século XX. A reflexão histórica justifica-se, no sentido de pontuar, nos períodos históricos, o desenvolvimento institucional e legal da formação do ensino em enfermagem. Esse processo faz-se necessário para a compreensão dos problemas da saúde que envolvem diretamente a enfermagem, uma vez que esses problemas produziram-se no passado e reproduzem-se no presente, originando daí a importância da investigação histórica para seu desvendamento e superação.

O estudo da formação desse profissional está articulado às interpretações das determinações legais e, em particular, das Leis de Diretrizes e Bases da Educação Nacional de 1968, Lei no 5540 de 1996 e Lei no 9394, nos capítulos referentes ao ensino superior, haja vista a articulação do propósito das leis com a definição de uma política de formação em enfermagem correlacionada ao desenvolvimento do ensino superior no país.

A metodologia contou com o levantamento de autores que abordam a temática da formação da enfermagem, bem como do desenvolvimento do ensino superior no Brasil. Igualmente, realizou-se o levantamento das legislações pertinentes ao tema, notadamente as Leis de Diretrizes e Bases da Educação Nacional, dos anos de 1968 e 1996, nos capítulos referentes ao ensino superior. Os dados pesquisados foram coletados de material impresso e on-line, mediante os quais procurou-se realizar reflexões e comentários a respeito do curso de enfermagem e da institucionalização da profissão de enfermeiro. 


\section{O desenvolvimento da educação em enfermagem no Brasil diante das reformas de ensino}

O desenvolvimento da educação em enfermagem teve início em 1890, com a Escola de Enfermagem Brasileira, criada pelo Decreto Federal no 791, de 27 de setembro de 1890 (BRASIL, 1890), sendo, posteriormente, denominada Escola de Enfermagem Alfredo Pinto, pertencente à Universidade do Rio de Janeiro (Unirio). A formação estabelecida na Escola tinha por modelo as Escolas Salpetrère, na França, com duração de dois anos de curso e currículo era voltado para assistência hospitalar, predominantemente curativo (GEOVANINI, 1995, p. 23). A Escola Alfredo Pinto foi dirigida por Mme. Panphiro, uma das pioneiras da Escola Ana Néry, e teve seu ensino reformado pelo Decreto de 23 de maio de 1939 que ampliou o curso para três anos.

Nesse período, a sociedade brasileira foi marcada por profundas transformações. No campo político a Proclamação da República, em 1889, a Primeira Guerra Mundial, de 1914 a 1916, e a denominada Revolução de 30, no Brasil. No campo econômico ocorreu a crise do ciclo cafeeiro e a aceleração industrial. No campo social ocorreu a urbanização, o processo de imigração e os movimentos sociais e, no campo cultural, o movimento liderado por artistas e intelectuais que culminou com a Semana de Arte Moderna, em 1922. O processo de industrialização, urbanização, imigração e oscilações na economia cafeeira junto à conjuntura internacional foram fatores decisivos na instauração de um novo quadro político e econômico nacional.

Ao ser deflagrada a Primeira Guerra Mundial, em 1914, como consequência de lutas pela hegemonia imperialista, a Cruz Vermelha Brasileira, passou a preparar voluntários para o trabalho de enfermagem, com a finalidade de auxiliar o trabalho com os feridos na guerra. Surgia então, a "Escola da Cruz Vermelha do Rio de Janeiro (1917), com um curso para socorrista e outro para voluntários" (GEOVANINI, 1995, p. 62). Os diplomas expedidos pela escola foram registrados, inicialmente, no Ministério da Guerra e considerados oficiais. No plano educacional, foi aprovada a Reforma Rivadávia Correia, pelo Decreto no 8.659, em 5 de abril de 1911, que instituiu a liberdade de ensino, quebrando o monopólio público da educação média e superior e criando o exame de vestibular (CUNHA, 1980, p. 162). 

formas de referências destacaram-se na profissionalização da enfermagem brasileira como um novo impulso na área da educação profissional e na ascensão da Saúde Pública, por meio da Reforma Carlos Chagas, que criou a Departamento Nacional de Saúde Pública, em 1920, e contou com a colaboração da enfermeira norte-americana M. Rice, chefe das visitadoras sanitárias do Departamento.

Nesse momento, em meio às lutas sociais relacionadas aos graves problemas de saúde que começaram a ser enfrentados pela população urbana, intensificou-se o processo de urbanização. A educação e a saúde passaram a fazer parte das políticas públicas do Estado, porém muito mais na forma de discurso e dispositivos legais do que de práticas sistematicamente implementadas que trouxessem benefício para a população.

As precárias condições de vida da população, aglomeração e imigração, foram fatores que facilitaram o aparecimento de doenças infectocontagiosas, agravando o quadro de saúde já existente. As epidemias, que já não eram novidade, ganharam, nessa conjuntura, outra dimensão, necessitando de medidas urgentes por parte do Estado e vindo a contribuir, nos primórdios da República, para que a saúde pública se tornasse preocupação do governo. Tanto que, nos primeiros anos de República, diversas instituições foram criadas para combater as questões epidêmicas e estabelecer medidas sanitárias que pudessem eliminar os focos contagiosos e melhorar as condições de saúde da população, conforme Costa (1986, p. 46) relaciona, dizendo:

[...] o governo instituiu o Conselho de Saúde Pública (1890); regulamentou o Laboratório de Bacteriologia (1892); criou o Instituto Sanitário Federal (1894), a Diretoria de Saúde Pública (1897); o Instituto Soroterápico Municipal (1900); instituiu a obrigatoriedade da vacina contra varíola e a Notificação de Doenças consideradas transmissíveis (1902).

Doenças como a febre amarela, o cólera, a peste e o sarampo passaram a ser de notificação compulsória. A febre tifóide e a tuberculose, apesar de altos índices de mortalidade, eram de notificação facultativa. As práticas sanitárias realizadas pelos serviços públicos concentraram-se na desordem urbana, no combate às doenças epidêmicas, no desregramento moral, na higiene e no controle de hábitos da sociedade. 
O movimento sanitarista pautou-se, na época, mais em

princípios da corrente bacteriológica e apresentou para a sociedade um projeto de intervenção, denominado:

[...] o campanhista policial - [...] que se baseava na intervenção da polícia sanitária na execução de campanhas. Essa estratégia de intervenção configurava-se em estruturas institucionais centralizadas, que se utilizavam das ações mais variadas para separar o universo dos sadios daquele dos doentes e/ou contaminados e, dessa forma, permitirem que o lado sadio se impusesse (MERHY, 1992, p. 69).

A questão sanitária também foi foco de atenção das organizações latino-americanas que, preocupadas com a relação entre os países do bloco e o intercâmbio econômico internacional, incorporam-se aos programas de saneamento público na América Latina, comenta Giovanini (1995, p. 24).

Por outro lado, o processo de desvinculação da atenção médica das associações latino-americanas reforçava a iniciativa dos Estados Unidos quanto à expansão dos programas de educação em enfermagem, tendo em vista que a organização do serviço de saúde pública brasileiro encontrava-se sob a orientação de enfermeiras norte-americanas, cujas práticas sanitárias eram assessoradas pela Fundação Rockfeller.

A proximidade das relações entre Brasil e Estados Unidos possibilitou o acordo com o Diretor do Departamento Nacional de Saúde Pública, Dr. Carlos Chagas, para enviar um grupo de enfermeiras que organizassem a primeira escola de enfermagem, Escola de Enfermagem Ana Nery, baseada na adaptação americana do modelo nigthingaleano da Escola Inglesa, fundada pela enfermeira Florence Nightingale, em 1859 (RIZZOTTO, 1999, p. 55). A Escola Ana Nery ficou subordinada, então, ao Departamento Nacional de Saúde Pública, com apoio da Fundação Rockfeller.

Em 1923, a primeira escola de enfermagem profissional surgia no Brasil, dirigida pela enfermeira Miss Clara Louise Kienninger. $\mathrm{O}$ curso iniciou com 14 alunas, em um pequeno internato próximo ao Hospital São Francisco de Assis, no Rio de Janeiro, tendo a primeira turma diplomada em 1925.

Por seu turno, a Escola Ana Nery refletia a contradição entre o discurso social e a prática elitista na área da saúde. Se por um lado, o discurso apontava a necessidade de enfermeiras para 
o trabalho preventivo, por outro enfatizava os benefícios de ter um pessoal qualificado para cuidar dos doentes particulares, nas residências e nos hospitais.

$\mathrm{O}$ processo de seleção das alunas na Escola foi rígido e elitista. O primeiro regimento interno da Escola Ana Nery exigia das alunas a apresentação de certificados de exames preparatórios de Português, Aritmética, Francês, Inglês, Geografia e História do Brasil, Física, Química e História Natural ou diploma da Escola Normal ou curso oficial equivalente. Exigia, ainda, idade entre 20 e 35 anos, atestado médico que comprovasse suas perfeitas condições físicas e mentais, atestado de boa conduta e estado civil de solteira, viúva ou separada legalmente do marido. Por essas exigências, pode-se inferir que não eram muitas as mulheres brasileiras com esses requisitos.

A preocupação era melhorar a imagem social do trabalho de enfermagem, para que houvesse interesse de jovens e senhoras brasileiras das melhores camadas sociais. Essa preocupação materializou-se com base nos princípios nightingaleanos, centrados na moral, na disciplina, no treinamento, no regime disciplinar, carregados de forte apelo moral e nos critérios para seleção das candidatas. A divisão social do trabalho, em enfermagem, caracterizou-se em um contexto de preparação de novas enfermeiras para executar tarefas de maior complexidade intelectual.

Segundo Cunha (1923, p. 5), os “[...] princípios norteadores, foram expressos no I Congresso Internacional de Higiene Infantil, realizado pela Sociedade Brasileira de Higiene, em 1923, intitulado Valor da Enfermeira nos Serviços de Saúde Pública”, cujos princípios eram os mesmos expressos por Florence Nightingale, em 1860.

A Escola Ana Nery, considerada escola padrão, tornou-se tradicional no contexto educacional brasileiro e personificou a imagem da enfermeira brasileira. Tanto que o Decreto no 20.109, de 15 de junho de 1931, estabeleceu que as demais escolas criadas para formação em Enfermagem deveriam funcionar, conforme os padrões da Escola Ana Néry.

Assim, o perfil exigido para a formação da enfermeira passou a ser elaborado por esse modelo (GEOVANINI, 1995, p. 24). Os critérios estavam fundamentados em princípios referendados pelo modelo americano, provenientes do modelo nightingaleano, 
que reproduziram e imprimiram as características de submissão, espírito de serviço, obediência e disciplina.

De acordo com Cunha (2007, p. 203), na década de 1920, algumas mudanças ocorreram na educação do País, por meio das reformas educacionais de Lourenço Filho, em 1924, de Anísio Teixeira, em 1925, e de Fernando de Azevedo, em 1928.

Outro marco importante na educação nessa área foi a fundação, em 1926, da Associação Nacional de Enfermeiras Diplomadas Brasileiras, atual Associação Brasileira de Enfermagem, entidade de direito privado, de caráter científico e assistencial, que congrega técnicos e enfermeiros diplomados brasileiros. A Associação foi juridicamente registrada em 1928 e filiada ao Conselho Internacional de Enfermeiros em 1929. Por um período, a Associação esteve inativa, tendo retomado os trabalhos em 1944, por um grupo de enfermeiros(as) diplomados(as), que passaram a contar com o estatuto aprovado em 1948. Suas comissões tiveram papel relevante no desenvolvimento da enfermagem brasileira, principalmente nos aspectos de legislação e educação.

Outras escolas de enfermagem começaram seus trabalhos, como a Escola Carlos Chagas, criada pelo Decreto no 10.925, sendo a primeira escola fora da capital da República. Inaugurada em 1933, pelo Diretor de Saúde Pública de Minas Gerais, a Escola destacou-se por ser pioneira entre as escolas estaduais ao diplomar enfermeiros(as) religiosos(as) no Brasil. Em seguida, foi criada a Escola Luisa de Marilac que, fundada e dirigida por religiosas, representou um avanço na enfermagem nacional. A Escola de Enfermagem de caráter confessional da Congregação Camiliana foi a Escola religiosa mais antiga no Brasil, preparando para o trabalho prático de enfermagem jovens estudantes seculares e religiosas de todas as congregações (ENFERMAGEM. ELLU).

Em 1931, houve a instalação do Ministério de Educação e Saúde, que teve como meta resolver a problemática educacional, cultural e de saúde da população. Segundo Cunha (2007, p. 206), a reforma Francisco Campos ${ }^{1}$ e a Constituição de 1934 coroaram um período de intensa efervescência intelectual e política, impulsionando a instalação de novas escolas para o ensino secundário e criando novas universidades. À União foi atribuída a competência privativa para as Diretrizes de Educação e Saúde Nacional e a renda dos estados e municípios vinculada a esses interesses. Também em 1931, criaram-se as normas legais para o exercício do ensino de enfermagem, período em que a enfermagem
1 Francisco Campos, primeiro Ministro da Educação, elaborou o Estatuto das Universidades Brasileiras, vigente por 30 anos, dando início à política educacional autoritária. Reforma de Ensino, em 1931. 
profissional estava voltada para as áreas de ensino e saúde pública, enquanto nos hospitais permanecia a prática de religiosas.

Em 1939, surge a Escola Paulista de Enfermagem, fundada por religiosas e que foi pioneira na renovação da enfermagem paulista. Uma das mais importantes contribuições da Escola foi o início da Pós-Graduação em enfermagem e obstetrícia. A Escola de Enfermagem da Universidade de São Paulo (USP), fundada em 1944, contou com a colaboração da Fundação de Serviços de Saúde Pública (ENFERMAGEM. ELLU).

$\mathrm{Na}$ década de 1940, a Escola Ana Nery foi incorporada à Universidade do Brasil e, em 1949, pelo projeto de Lei $\mathrm{n}^{\circ}$ 775 , aprovado pelo Decreto no 27.426, estabeleceu a expansão das escolas e a incorporação da educação em enfermagem aos centros universitários. Em 1961, a Lei de Diretrizes e Bases da Educação Nacional passou a exigir ensino secundário completo ou equivalente para ingresso em escolas de enfermagem, que foram instituídas no ensino superior (GIOVANINI, 1995, p. 25).

\section{As mudanças no cenário nacional e os encaminhamentos da formação em enfermagem}

As décadas compreendidas entre os anos de 1930 e 1960 foram marcadas por amplas transformações no cenário nacional, que tiveram início com o período do Governo Vargas, seguido da queda do Estado Novo, do retorno ao Estado Democrático e da volta de Vargas ao poder, em 1950. Em 1955, ascendia ao governo Juscelino Kubitschek que empreendeu, no cenário econômico, a integração do sistema capitalista ocidental que teve repercussão no contexto da educação nacional (ALENCAR; RAMALHO; RIBEIRO, 1985).

Nesse período, evidenciou-se a inclinação dos centros de poder para atender os problemas de saúde, oriundos do processo de acumulação capitalista, direcionado para as funções reprodutivas da força de trabalho. A ordem do sistema de saúde, pressionada pelo movimento dos trabalhadores em defesa de seus direitos,

2 Em 1951, houve a separação do Ministério da Saúde e da Educação, pelo Decreto 1920/53, permanecendo o Curso de Enfermagem subordinado ao Ministério da Saúde. sofreu expansões e modificações, conforme a conjuntura política do momento (MERHY, 1992).

Uma das principais mudanças administrativas na esfera federal foi a separação dos Ministérios da Saúde, da Educação e Cultura, que ocorrera em 1953². O curso de enfermagem permaneceu vinculado ao Ministério da Saúde, conforme previsto 
na Lei no 1.920 , de 25 de julho de 1953, que assim estabelecia: "Art. 10 É criado o Ministério da Saúde, ao qual ficarão afetos os problemas atinentes à saúde humana." (BRASIL, 1953). Assim, todas as questões que afetavam a área da saúde ficaram subordinadas à administração e à fiscalização do Ministério da Saúde, entre elas os cursos de enfermagem.

Nesse quadro administrativo, a educação nacional em enfermagem, já consolidada aos programas universitários e governamentais, contava com enfermeiros e enfermeiras inseridos no contexto hospitalar, além do crescimento quantitativo de outras categorias da enfermagem, de acordo com as novas exigências do mercado. Cabe esclarecer que o exercício da profissão foi regulamentado pela Lei no 2.604/55 (BRASIL, 1955), e o registro de diplomas de enfermeiros, expedidos até o ano de 1950, foi regulamentado pela Lei no 2.822/56 (BRASIL, 1956), tendo em vista a nova condição de formação em nível superior e a formação prática que aumentava o número de atendentes e auxiliares de enfermagem.

Outro evento que reforçou a desordenada expansão do pessoal de enfermagem foi a criação do Instituto de Previdência Social $^{3}$, em 1966, em decorrência do atendimento médico individualizado exigido pelos trabalhadores, o que reforçou a política de saúde médico-hospitalar e relegou a saúde pública a uma posição secundária (GIOVANINI, 1995, p. 26).

Ainda teve relevância para o setor de saúde, na década de 1960, a instituição do Sistema Nacional de Saúde, em 1964, surgindo como modelo autoritário e burocrático no país. A educação foi marcada por reformas, destacando-se a Reforma Universitária, pela Lei no 5.540, de 28 de novembro de 1968, que reafirmou os princípios já adotados em legislações anteriores e a estrutura em fase de implantação. Mediante a legislação ficava estabelecido que o ensino superior passasse a ser ministrado em universidades e, excepcionalmente, em estabelecimentos isolados.

Assinala-se que a Reforma Universitária, Lei no 5.540/68, aprovada no período de governo do regime político militar, teve como pressuposto o desenvolvimento da racionalidade da gestão educacional. "Essa política de aglutinação faz parte da política de concentração de esforços e recursos materiais e humanos para obtenção de maior economia de aplicação de recursos e maior produtividade", comenta Romanelli (1986, p. 228). Essa política teve por base a teoria do investimento econômico no denominado "capital humano".
3 O Instituto Nacional de Previdência Social, criado em 1966 a partir da unificação das aposentadorias e pensões, consolidou o modelo de medicina previdenciária no País (GIOVANINI, 1995, p.26). 
Em relação ao ensino e à formação nos cursos de enfermagem destacou-se, nessa fase, a Escola de Enfermagem Alfredo Pinto, que passou a ser uma das unidades integradas da Federação de Escolas Federais Isoladas do Estado da Guanabara, mais tarde Federação das Escolas Federais do Estado do Rio de Janeiro (FEFIEG), cuja finalidade foi reunir e integrar os estabelecimentos isolados ao sistema federal de ensino superior sob a forma jurídica de fundação.

\section{As novas perspectivas para a formação de enfermagem}

De acordo com a Reforma Universitária, Lei no 5.540/68, novos caminhos foram abertos para a enfermagem, que caracterizou-se por um crescimento acadêmico, com a admissão no corpo docente da categoria de auxiliares de ensino e determinação do uso de uniformes para docentes em salas de aula e aulas práticas. $\mathrm{O}$ objetivo foi o de identificar uma organização da prática docente, destacando-se a promoção de cursos de especialização em didática, na FEFIEG e a estruturação de curso para livre docência, visando o aperfeiçoamento técnico-científico dos docentes (GIOVANINI, 1995, p. 26-27).

A preocupação com a pesquisa foi outro ponto focalizado para ajustar-se à política de desenvolvimento do país. A filosofia desenvolvimentista foi o fundamento que norteou os programas de educação e saúde voltados para a nação e para a responsabilidade na obra educativa ao qual se propunha o governo militar.

Rodrigues et al (2008) relatam que o primeiro Curso de Mestrado em Enfermagem no País foi criado pela Escola de Enfermagem Ana Néry, da Universidade Federal do Rio de Janeiro, em 1972, seguindo-se a criação de outros em diversas regiões do Brasil. Na década de 1980, as possibilidades de formação ampliaram-se com a criação do Curso de Doutorado, em 1981, pela Escola de Enfermagem da Universidade de São Paulo (USP) e pela Escola de Enfermagem de Ribeirão Preto, também da USP, que, na modalidade interunidades, inaugurou uma nova era na enfermagem, com a criação do primeiro Curso de Doutorado no país e na América Latina.

Essas iniciativas tiveram reflexos positivos na formação em Enfermagem, pois permitiram impulsionar o desenvolvimento de pesquisas, atendendo às prioridades nacionais, afirmam Rosalina Rodrigues et al (2008). 
Em 1982, foi criado o Curso de Mestrado em Ciências da

Enfermagem na Universidade do Rio de Janeiro (Unirio), com a finalidade de preparar e desenvolver recursos humanos para o magistério superior, atendendo aos dispositivos legais estabelecidos nas políticas educacionais do país de preparar docentes em nível de excelência, aprimorar o exercício do magistério superior e formar pesquisadores (UNIRIO. 2014).

Conforme os dados fornecidos pelo Portal do PPGE/ UNIRIO (2014), o Curso de Mestrado conta com trinta e um anos de funcionamento, tendo titulado, até dezembro de 2012, 436 enfermeiros. A evolução da Pós-Graduação foi acompanhada pela evolução acadêmica do Curso de Enfermagem, com ênfase na pesquisa e na produção científica.

A formação acadêmica em nível de Pós-Graduação não se tornou relevante no cenário de trabalho que os órgãos públicos e particulares necessitavam, considerando a urgência de mãode-obra prática que era preparada nos cursos técnicos e de treinamento prático. Apesar do modelo de assistência adotado pela previdência que determinou a ampliação do campo prático de enfermagem, foram, todavia, os órgãos públicos que absorveram mais profissionais de nível superior, enquanto o setor privado absorveu as categorias de auxiliares e operacionais de enfermagem, em razão da política de redução de custos. A estratégia de redução de despesas foi observada na educação em enfermagem quando os currículos passaram a privilegiar o ensino especializado e a assistência curativa. Com isso, houve a proliferação de cursos de menor custo, como os que foram organizados para treinar atendentes, auxiliares e técnicos de enfermagem.

Nesse sentido, a composição heterogênea da enfermagem, no Brasil, foi reforçada pelo sistema de formação que, para atender o mercado, levou à fragmentação e à subdivisão na área. A fragmentação de trabalho foi elemento desencadeador da distinção de diferentes categorias em uma equipe de enfermagem que, todavia, não se tornava perceptível pela sociedade em geral.

Todavia, cabe ressaltar que a dicotomia entre curso superior e curso técnico ou prático, a qual instalou-se na formação em enfermagem, nada mais foi que a extensão de uma prática educacional que fora implantada na década de 1930, com a criação dos cursos técnicos do Senac e do Senai, destinados às camadas sociais de baixa renda que, em contrapartida, atenderiam as necessidades do mercado de trabalho. Os cursos superiores 

(ROMANELLI, 1986).

A tendência pela formação prática teve repercussões na concepção de formação dos próprios alunos, pois gerou $\mathrm{o}$ pragmatismo na formação de enfermagem. As discussões teóricas que não tivessem aplicabilidade imediata ficavam de lado, evidenciando uma resistência por parte dos futuros enfermeiros. Tanto que no ambiente de trabalho e até de formação dificilmente ocorriam discussões a respeito de concepções, conceitos, princípios e diretrizes que fundamentariam a prática profissional, partindose do pressuposto que tais discussões eram irrelevantes. $\mathrm{O}$ exercício da profissão acabava reduzindo-se ao voluntarismo ou ao ativismo que compensavam ou camuflavam as frustrações dos resultados esperados no projeto profissional.

A dicotomia na prática profissional, representada pelo saber e o fazer dos enfermeiros e do pessoal operacional, atendia ao modelo administrativo que regia as instituições, fragmentando o processo do trabalho em favor da disciplina e da organização e, paralelamente, favorecendo a alienação profissional.

\section{As mudanças na estrutura social e no quadro político nacional}

$\mathrm{Na}$ década de 1970, ocorreram transformações importantes na estrutura social do país, decorrentes, em grande parte, das mudanças no quadro político nacional. Em 1973, foi criado o Conselho Federal de Enfermagem (BRASIL, 1973), órgão disciplinador do exercício profissional e dos sindicatos defensores dos direitos econômicos e das condições de trabalho dos profissionais da enfermagem.

A partir de 1975, um novo modelo foi definido, por meio da Lei no 6.229, do Sistema Nacional de Saúde (BRASIL, 1975), posteriormente revogada, em 1990, pela Lei no 8.080, que instituiu o Sistema Único de Saúde (SUS). Segundo Giovanini (1999, p. 27), a "Lei [ no 6.229/75] legitimou a pluralidade institucional no setor de Saúde e identificou a Previdência social, como responsável pela assistência individual e curativa, e o Ministério da Saúde, por meio das secretarias, pelos cuidados preventivos". Por meio da Lei no 6.229, tentava-se ampliar os serviços de saúde em um momento de forte crise financeira, racionalizando recursos e inviabilizando metas. 
Entretanto, apesar da crise financeira, esse período foi o mais intenso da produção científica em enfermagem, em decorrência do aumento do número de cursos de Pós-Graduação que acelerou seu ritmo. Ao mesmo tempo, ocorria à convergência dos profissionais de enfermagem para a área de treinamento, coordenação e supervisão. Essa movimentação na área de enfermagem culminou com a criação do Centro de Estudos e Pesquisas em Enfermagem (CEPEn) ${ }^{4}$ e da Associação Brasileira de Enfermagem (ABENn). Dessa forma, a enfermagem ampliou seu espaço de atuação e firmou-se ao longo do desenvolvimento da construção de sua identidade profissional. Como colocam Peres et al (2014, p. 85):

A enfermagem se [inseriu] em diferentes espaços, onde o cuidado [foi] necessário e onde foi possível a construção de saberes, que ao longo do tempo foi adquirindo respaldo em busca da cientificidade. Podemos citar o espaço doméstico, assistencial, acadêmico, profissional, associativo, entre outros.

Há de se considerar que, para essa longa caminhada profissional, concorreu a formalização gradativa dos cursos de enfermagem e daqueles, em nível de pós-graduação, latu sensu, que começaram a ser criados na década de 1940. Porém, somente a partir de 1974 passaram os cursos de pós-graduação a receber atenção especial e vieram não só atender a demanda de enfermeiros qualificados para o magistério, originada pelo número de cursos de graduação, mas também de especialização crescente da medicina e dos padrões sofisticados da tecnologia hospitalar.

Cabe ressaltar que o impulsionamento ocorrido nos cursos de enfermagem deveu-se, em grande parte, à Reforma Universitária de 1968, que favoreceu formação na área em nível superior a partir da inserção da carreira e da integração dos cursos existentes e dos novos que foram sendo criados nas universidades. A inserção da carreira no ensino superior deu nova perspectiva de formação e descortinou horizontes mais favoráveis para o aperfeiçoamento acadêmico.

Rocha e Nunes (2013) comentam que, embora tenha ocorrido o aumento de cursos superiores no início da década de 1970, havia, ainda, a necessidade da criação de outros cursos, considerando que os registros do Ministério de Educação e Cultura (MEC) apontavam estimativas muito aquém do índice de 4,5 enfermeiros por 10.000 habitantes, como era recomendação do Plano Decenal de Saúde para as Américas.
4 CEPENn - Centro de Estudos e Pesquisas com o objetivo de promover e incentivar a pesquisa na enfermagem, bem como organizar suas áreas de interesse. 
Uma política de ampliação de cursos de enfermagem tornouse prioridade do MEC, por meio do Departamento de Assuntos Acadêmicos (DAU/MEC), para a instalação de novos cursos nas universidades públicas federais.

Com o trabalho desenvolvido por esse órgão [DAU/MEC] ocorreu novamente a expansão dos cursos de enfermagem no Brasil, sendo que de 1966 a 1970 foram criados cinco cursos, de 1971 a 197516 cursos e de 1976 a 198034 cursos. Ainda de 1981 a 198515 cursos e de 1986 a 1993 mais doze cursos foram criados. A partir da década de 1980, o contexto da evolução dos cursos de enfermagem no Brasil, veio se modificando em virtude da retração do ensino público e avanço do ensino privado, por razões do aprofundamento das dificuldades do quadro econômico nacional, que redefiniu a política educacional do País, especialmente do ensino superior (ROCHA; NUNES, 2013, p.3-4).

Sem dúvida, há de se ressaltar que o consenso, em torno de cursos de pós-graduação e educação continuada, tornou-se imprescindível para a prática. No entanto, essa ação poderia ser efetivada a partir de uma revisão dos currículos para melhorarem a qualidade da assistência e o desenvolvimento da consciência crítica dos enfermeiros.

A partir de 1980, com a aprovação da Lei no 7498/865

5 Conselho Federal de Enfermagem " Dispõe sobre a regulamentação do exercício da Enfermagem, D.O.U. de 26/06/86, Seção I, fls. 92739275 . (BRASIL, 1986) em substituição à Lei no $2.604 / 55$, ocorreram avanços para enfermagem, trazendo novas disposições para o exercício profissional. A Lei reconhecia a categoria do enfermeiro, do técnico de enfermagem, auxiliar de enfermagem e da parteira, determinando a extinção, em 10 anos, do pessoal sem formação específica, regulada em lei. No entanto, na prática não houve mudanças expressivas, permanecendo os enfermeiros insatisfeitos em relação ao seu papel na sociedade.

Em 1984, outro evento proporcionou uma perspectiva mais pragmática à integração ao setor público. A estratégia, efetivada por meio do Programa de Ações Integradas de Saúde, como a Proposta institucional do INANPS, assumido pelas Secretárias de Saúde dos Estados e pelo Ministério da Saúde, Previdência e Educação, com vistas à ação conjunta, consistia na integração das instituições em nível federal, estadual e municipal para a melhoria da qualidade da assistência, descentralizando, universalizando e hierarquizando os serviços.

Segundo Giovanini (1995, p. 26), essas diretrizes institucionais pactuaram com a ideologia e com os movimentos 
de Reforma Sanitária e do Sistema Único de Saúde, incorporado à nova Constituição6, adotando com isso o conceito de saúde coletiva. Nessa perspectiva de reformulação do sistema de saúde, a enfermagem teve como desafio a redefinição da sua prática nos serviços e o redirecionamento da formação do pessoal de enfermagem em todos os níveis.

Na década de 1990, os avanços populares rumo à organização estavam implícitos nos movimentos sociais e nas políticas defendidas pelos partidos de esquerda, criando condições para o povo exercer seus direitos e eleger, diretamente, o Presidente da República. O novo Governo, instalado em 15 de março de 1990, com o discurso de combate à inflação e construção de um Brasil novo, privilegiou o modelo neoliberal por meio de uma série de medidas econômicas que culminaram com agravamento da pior crise social da história.

$\mathrm{Na}$ perspectiva da formação humana [...], ao mesmo tempo em que se delineia o âmbito da construção teórica, exercita-se no plano do embate político e organizativo da educação, tanto no contexto do processo constituinte, quanto no processo de elaboração e definição da Lei de Diretrizes e Bases da Educação Nacional, que está em gestão desde 1988. A luta, no plano das diretrizes e no plano das bases (condições de concretização das diretrizes), dá-se dentro do tecido social e cultural, onde as elites dirigentes fazem o discurso da modernidade (FRIGOTTO, 2003, p. 48).

Nesse contexto, a enfermagem especializava-se cada vez mais para atender as expectativas médico-hospitalares e direcionava-se a resgatar a saúde pública no Brasil. Dentre as iniciativas em prol da saúde coletiva, destacava-se o papel assumido nas consultas de enfermagem, servindo como mediador entre esta e o sistema de saúde, atuando com tecnologia simplificada e de baixo custo, tendo como foco a educação em saúde e ênfase no autocuidado.

A nova postura da categoria incentivou a inter $\mathrm{e}$ multidisciplinaridade, com o objetivo da manutenção da saúde do homem, integrado ao seu ecossistema, vencendo a abordagem biologista7 e tecnológica. Em meio a essas ilhas, o enfermeiro assumiu posição de comando, embora quase sempre subordinado à categoria médica.

A extrema dependência do setor público em relação ao setor privado e o descomprometido com os interesses sociais deixavam a população à margem do sistema de saúde. $\mathrm{O}$ resurgimento de
6 Artigo 199, da Constituição do Brasil, Assembleia Nacional Constituinte. Constituição da República Federativa do Brasil, 5/out/1988. 
176 Revista Grifos

7 Abordagem referendada no paradigma médico e curativo. doenças evitáveis, como tuberculose, hanseníase, febre amarela e cólera e o surgimento da AIDS, foram fatores que expressaram a situação caótica da crise da saúde brasileira.

A IX Conferência Nacional de Saúde, em 1992, aconteceu no momento em que o desmando e a corrupção no governo eram apurados pela conclusão da Comissão Parlamentar de Inquérito, depondo o Presidente da República, Fernando Collor de Melo. Nesse clima, a conjuntura enfrentava a crise ética e política no país, que culminou com os trabalhos da IX Conferência Nacional de Saúde. Com isso, a atuação das Comissões Éticas foi mais incisiva, deflagrando o processo de auditoria em órgãos públicos e privados.

Dentre as propostas abordadas na questão dos recursos humanos, destacou-se a regulamentação do art. 200, III, da Constituição Federal (BRASIL, 1988), que atribuía ao SUS a tarefa de ordenar a formação dos recursos humanos e a revisão completa dos currículos profissionais, adequando-os à realidade socioepidemiológica.

A revisão previa a inserção, no currículo de formação dos profissionais de saúde, de estágio na rede básica de serviços para permitir um íntimo contato com as realidades locais, objetivando a adequação profissional à realidade social e à inclusão de práticas alternativas. A postura de rompimento da fragmentação dos currículos e da visão biologicista previa a adequação da formação ao novo paradigma da ciência, trabalhando a teoria de forma interdisciplinar e articulada ao contexto histórico, coloca Geovanini (2002, p. 31-32).

Em 1985, a Associação Brasileira de Enfermagem em conjunto com as Comissões de Especialistas em Enfermagem das Secretarias de Educação desenvolveram um estudo de âmbito nacional, visando definir os parâmetros e diretrizes básicas na orientação da formação do enfermeiro no Brasil. A proposta em pauta, estabelecida no Seminário sobre Currículo Mínimo, em Niterói, em 1989, foi constituída por meio de documentos da ABEn, apresentados em 1991.8

As alterações envolveram a extinção das habilitações, o aumento da duração mínima do curso, de 2.500 h. para 3.000 h., distribuídas de oito a dez semestres letivos, conforme Parecer n. 163/72, o redimensionamento dos conteúdos, incluindo conteúdos pertinentes à capacitação para o ensino de $1^{\circ}$ e $2^{\circ}$ graus, 
e a mudança do nome do curso, de enfermagem e obstetrícia para Curso de Enfermagem (GEOVANINI, 1995, p. 32).

A "Lei 9.394, de 1996, institui a nova Lei de Diretrizes e Bases da Educação brasileira" relacionada à organização da educação superior. Tal reforma caracterizou o processo histórico de democratização da sociedade brasileira, destacando-se as finalidades de incentivar o trabalho de pesquisa e a investigação científica, tendo como objetivo promover o desenvolvimento da ciência e da tecnologia. Assim, a questão da formação do enfermeiro deveria levar em consideração tal princípio (SOUZA, 1997, p. 23).

Paul Singer (2001) assim se manifestou em relação ao momento vivido nesse final e início de séculos:

Estamos vivendo uma nova Revolução Industrial, a terceira desde o fim do século XVIII. É uma explosão de novos produtos, novos serviços e novos modos de produzir e distribuir. E tudo isso se atribui à ciência e à tecnologia, que frequentemente se confundem, como se fossem a mesma coisa. O entusiasmo pelos novos inventos e pela melhora da qualidade de vida que eles oferecem aos que podem usufruí-los passa sem hesitação à ciência, vista como a grande responsável por este progresso. Hoje, mais do que nunca, crê-se na ciência como forma suprema de conhecimento, deixando à sombra outros modos de conhecer, como a religião, a arte e a filosofia (SINGER, 2001, p. 305).

Em meio aos avanços científicos e tecnológicos, a relevância da estrutura curricular do curso de enfermagem sedimentou-se nos saberes teóricos e práticos para a formação do enfermeiro. $\mathrm{O}$ curso de Graduação de Enfermagem passou a ser regido pelo Parecer do Conselho Nacional de Educação (CNE) e da Câmara de Ensino Superior (CES) no 1.133, de 7 de agosto de 2001, que constituiu-se peça do conjunto de Diretrizes Curriculares Nacionais dos Cursos de Graduação em Enfermagem, Medicina e Nutrição para as instituições de ensino superior homologadas pelo Senhor Ministro da Educação, em 10 de outubro de 2001 (CNE/CES 1133, 7 ago 2001).

O Parecer do CNE/CES deu o suporte legal para a aprovação das Diretrizes Nacionais Curriculares do Curso de Graduação em Enfermagem, Resolução CNE/CES no 3, de 7 de novembro de 2001, que estabeleceu os objetivos de formação, centrados nas competências e habilidades e a serem observados nas instituições
8 ABEn. "Proposta de novo currículo mínimo para o curso superior de Enfermagem: a formação do Enfermeiro". Brasília, 1991. 
integrantes do Sistema de Educação Superior, ressaltando os aspectos de:

a) Atenção à saúde - estarem os futuros enfermeiros aptos a desenvolver ações de prevenção, proteção e reabilitação da saúde, tanto em nível individual quanto coletivo.

b) Tomada de decisões - desenvolver a capacidade de tomar decisões, visando o uso apropriado, a eficácia e o custo-efetividade da força de trabalho, de medicamentos, equipamentos, procedimentos e práticas.

c) Comunicação - desenvolver a acessibilidade no trato com as pessoas e, principalmente, os enfermos, a confiabilidade das informações obtidas e estabelecer a interação com outros profissionais da saúde e o público em geral.

d) Liderança - estar apto a assumir posições de liderança, visando o bem-estar da comunidade.

e) Administração e gerenciamento - estar apto a tomar iniciativas, saber gerenciar e administrar a força de trabalho, os recursos físicos e materiais e as informações, bem como ser empreendedor, gestor e empregador ou líder.

f) Educação permanente - ser capaz de aprender continuamente, ter responsabilidade e compromisso com sua educação, mantendo-se atualizado.

Os objetivos, em número de trinta e três, elencados no Art. $5^{\circ}$, culminaram com as palavras contidas no Parágrafo Único, que contêm, de maneira geral, o sentido dos objetivos de formação, que assim se expressam: "A formação do Enfermeiro deve atender as necessidades sociais da saúde, com ênfase no Sistema Único de Saúde (SUS) e assegurar a integralidade da atenção e a qualidade e humanização do atendimento" (CNE/CES Resolução 3/2001, p. 2, 3). Por sua vez, o Art. $2^{\circ}$ especifica em dois incisos, os valores, os princípios e o desenvolvimento de capacidades que deverão ser trabalhados para traçar o perfil do egresso/profissional:

I - Enfermeiro, com formação generalista, humanista, crítica e reflexiva. Profissional qualificado para o exercício de Enfermagem, com base no rigor científico e intelectual e pautado em princípios éticos. Capaz de conhecer e intervir sobre os problemas/situações de saúde-doença mais prevalentes no perfil epidemiológico nacional, com ênfase na sua região de atuação, identificando as dimensões bio-psicosociais dos seus determinantes. Capacitado a atuar, com senso de responsabilidade social e compromisso com a ci- 
dadania, como promotor da saúde integral do ser humano; e

II - Enfermeiro com Licenciatura em Enfermagem capacitado para atuar na Educação Básica e na Educação Profissional em Enfermagem (CNE/CES Resolução 3/2001, p. 1).

Embora a Resolução contenha palavras enaltecedoras de formação, visando a atuação do enfermeiro, as duas primeiras décadas do século XXI vão contar com um quadro pouco animador na área da saúde, tendo em vista as dificuldades que o sistema de saúde vem enfrentando e a falta de investimento dos governos. Contraditoriamente, as diretrizes governamentais traçam objetivos, competências e habilidades em um esforço para tornar a formação do profissional enfermeiro compatível com o avanço da ciência e da tecnologia. Entretanto, tais esforços não encontram ressonância na efetividade das políticas de governos no sentido de equalizar a formação científica e os elevados padrões de assistência à saúde recomendados pela Organização Mundial de Saúde, Organização Pan-Americana de Saúde e outras entidades nos diversos ambientes de atendimento à população, como postos de saúde, unidades de pronto-atendimento, hospitais entre outros.

Os propósitos que orientam a formação científicointelectual do profissional enfermeiro não correspondem, todavia, na prática, com o que está previsto na legislação, prejudicando o bom desempenho do profissional. Os propósitos de atuação do enfermeiro ficam muito mais no plano do discurso oficial e legal do que na efetividade prática das atividades previstas para a categoria desse profissional.

A Resolução n 3/2001, no Art. $6^{\circ}$, traz o elenco dos conteúdos essenciais para o Curso de Graduação em Enfermagem, os quais estão relacionados a todo o processo de saúde-doença do cidadão, da família e da comunidade, integrado à realidade epidemiológica e profissional que vão embasar as ações do cuidar em enfermagem. Dessa forma, os conteúdos contemplam estudos de Ciências Biológicas, da Saúde e da Enfermagem, não deixando de indicar os conhecimentos das Ciências Humanas e Sociais, uma vez que o papel desempenhado pelo profissional enfermeiro está altamente vinculado às relações interpessoais, seja individualmente com o paciente, seja com a família ou com o público, em geral.

As Diretrizes Curriculares Nacionais para o Curso de Graduação em Enfermagem, conforme constam na Resolução no 3/2001, priorizam os estudos das Ciências Biológicas, da Saúde e da Enfermagem, buscando contemplar a formação do enfermeiro 
com conhecimentos específicos para atuação em sua área de trabalho, de forma diversa daquele currículo proposto no início do século XX, para o curso da Escola de Enfermagem Ana Nery, no qual predominavam os conhecimentos da área de Ciências Humanas ao lado de estudos de Física, Química e História Natural.

O século XXI inaugura um novo modelo de formação, mais compatível com a realidade brasileira, no qual a teoria interligada à atividade prática, por meio de treinamentos, estágios curriculares, atividades complementares, monitorias, programas de extensão e de iniciação científica e outras participações, possibilita a consecução da práxis. Essa formação, tendo por orientação as diretrizes curriculares, deve propiciar ajustes nas concepções do Curso, visando o seu aperfeiçoamento. Isso porque as DCNs flexibilizam a participação das Instituições Superiores, públicas e privadas, nos processos de avaliação do ensino-aprendizagem e do próprio curso, em consonância com a dinâmica definida pela Instituição à qual o curso pertence, conforme estabelece a Resolução no 3/2001.

Em razão das mudanças que operaram nas orientações oficiais para os cursos de graduação, chama a atenção a nova perspectiva de formação do profissional enfermeiro. As transformações que ocorreram no transcurso do século XX, proporcionadas pelo avanço da ciência e da tecnologia, interferindo na economia e nos meios de comunicação, em nível mundial, notadamente nas últimas décadas daquele século e nas primeiras do século XXI, repercutiram na visão e na perspectiva de formação do perfil do egresso/profissional enfermeiro. Se, no início do século XX, o perfil do egresso era caracterizado pela submissão, espírito de serviço, obediência e disciplina, no final desse século e início do

9 Ver CNE/CES Resolução CNE/CES no 3 /2001. Diário Oficial da União, Brasília, nov/2001. Seção 1, p.37. século XXI, tem-se o propósito de traçar um perfil de egresso mais arrojado, decidido, empreendedor, gestor e líder. ${ }^{9}$

Observa-se a mudança de postura exigida no trabalho e nas ações empreendidas pelo profissional enfermeiro, não mais submetido às ordens ou mandos da categoria médica, mas colocando-o em um mesmo plano de formação científicointelectual que permita a troca de idéias, procedimentos e atendimento aos pacientes e ao público em geral. Afinal, os objetivos de formação desse profissional passam, obrigatoriamente, pelas novas exigências do mercado de trabalho, no qual não mais se admite o despreparo e o desconhecimento científico e 
intelectual. O plano de formação tem que estar equalizado aos demais profissionais da área da saúde, envolvendo o tripé de ensino pesquisa e extensão.

A universidade brasileira, desde sua criação, comenta Romanelli (1986, p. 133), “[...] vem perseguindo objetivos e propósitos de formação profissional, salvo exceções, priorizando o ensino sem garantir a pesquisa que acaba sendo relegada ao segundo plano".

No decorrer do século XX, esses objetivos sofreram mudanças em vista das transformações que operadas em escala mundial, não mais admitindo-se a mera formação profissional sem o respaldo e o fundamento científico, calcados nas atividades de pesquisa. A falta de tradição de pesquisa decorrente da estratificação social, da herança cultural, da lenta evolução econômica e industrial do País tem que ser revertida para uma nova postura de aprendizado, aliando a doutrina à prática para o desenvolvimento do pensamento reflexivo e crítico.

Como volta a frisar Romanelli (Ibid), "A investigação científica e o preparo para o exercício profissional, têm sido, na verdade, os reais objetivos da Universidade Moderna”. Se esses são os objetivos de uma universidade moderna, nada mais certo que incentivar o desenvolvimento de atividades de pesquisa cientificamente comprovadas, nos meios acadêmicos, para permitir e viabilizar uma formação intelectual e científica adequada aos novos tempos.

\section{Considerações finais}

A compreensão do contexto histórico do processo de desenvolvimento da educação da enfermagem, no Brasil, desde a criação da primeira escola para formação de enfermeiros de 1890 até o período atual, procurou descrever e explicitar o referido contexto a partir das legislações que deram os encaminhamentos legais à formação do profissional, bem como as determinações previstas nas Leis de Diretrizes e Bases para o ensino superior. A Lei no 5.540/68 e a Lei no 9.394/96 destacamse como referenciais norteadores da discussão para fundamentar a formação do enfermeiro. Cabe ressaltar, as Diretrizes Curriculares Nacionais do Curso de Graduação em Enfermagem, estabelecidas pelo Conselho Nacional de Educação e Câmara de Ensino 
Superior, em 2001, que trouxeram novas e modernas perspectivas e objetivos de formação.

De acordo com a história da educação no país, observa-se a presença de contradições sociais que permearam a realidade desse profissional, em decorrência da relevância econômica, sempre presente como determinante para a organização das políticas de reforma e desenvolvimento.

A presença do caráter racional da gestão pública articulada ao processo histórico de desenvolvimento econômico permitenos constatar, em ambas as legislações, o caráter centralizador do regime político militar da Reforma de 1968 (Lei no 5.540).

Em relação à enfermagem, observou-se um desenvolvimento pautado na fragmentariedade da categoria, cujo objetivo foi atender a demanda do mercado, minimizando custos para o governo. Nesse sentido, impõe-se um debate sobre a qualidade da formação, articulada à prática profissional e ao status social desse profissional. A preocupação com o preparo científico e intelectual do profissional em enfermagem foi em estabelecer marcos que privilegiassem discussões a respeito da postura crítica e reflexiva condicionada à realidade social.

No entanto, a LDBEN, Lei no 9.394, de 1996, diversamente da Lei no 5.540, de 1968, privilegiou o caráter determinista de racionalização do mercado, em relação à formação do enfermeiro, no sentido de atender expectativas do neoliberalismo e da globalização do mercado.

No referido contexto, firma-se a ideia de que a crise da enfermagem, neste início de século XXI, decorre de aspectos relacionados: primeiro, ao caráter da formação intelectual, que não objetiva a especificidade dessa formação, o que é demonstrado pela formação mais técnica. Segundo, esse aspecto está articulado ao primeiro, uma vez que o profissional apresenta dificuldade de atender ao mercado devido à sua carência de base intelectual e crítica frente à realidade. Por essa razão, é necessário realizar mudanças prementes na postura de formação desse profissional, conscientizando os cursistas da necessidade de aprofundamento de estudos e pesquisas que possam fundamentar o exercício prático de sua atividade profissional.

$\mathrm{O}$ esforço do referido trabalho, teve como objetivo compreender historicamente o desenvolvimento da educação em enfermagem, inserindo-o no quadro das contradições sociais e políticas. Esta reflexão compõe-se de uma discussão que deverá 
ser retomada para aprofundamento das questões que permeiam a realidade desses profissionais na atualidade.

\section{Referências}

ALENCAR, F.; RAMALHO, L. C.; RIBEIRO, M. V. T. História da sociedade brasileira. 3. ed. Rio de Janeiro: Livro Técnico, 1985.

BRASIL. Coleção de Leis do Brasil - 1890, v./fasc.IX, p. 2456. Decreto no 791, de 27 de setembro de 1890. (Publicação Original). Disponível em: <http://www2.camara.leg.br/ legin/fed/decret/1824-1899/decreto791-27-setembro-1890-503459-norma-pe.html>. Acesso em: 8 set. 2014.

Constituição (1988). Constituição: República Federativa do Brasil. Brasília, DF: Senado Federal, 1988.

. Presidência da República. Casa Civil. Subchefia para Assuntos Jurídicos. Lei no 1.920, de 25 de julho de 1953. Disponível em: <http:// www.planalto.gov.br/ccivil_03/leis/ 1950-1969/L1920.htm>. Acesso em: 28 out. 2014.

. Lei no 2.604, de 17 de setembro de 1955. Regula o exercício da enfermagem profissional. Disponível em: <http://presrepublica.jusbrasil. com.br/legislacao/128763/lei-2604-55 >. Acesso em: 10 out. 2014.

Câmara dos Deputados. Lei no 2.822, de 14 de julho de 1956. Dispõe sobre o registro de diploma de enfermeiro, expedido até o ano de 1950, por escolas estaduais de enfermagem não equiparadas, nos termos do Decreto no 20.109, de 15 de junho de 1931 e da Lei no 775, de 6 de agosto de 1949 e dá outras providências. Disponível em: <http://www2. camara.leg.br/legin/fed/lei/1950-1959/lei-2822-14-julho-1956355066-norma-pl.html>. Acesso em: 10 out. 2014.

Presidência da República. Lei no 5.540 , de 28 de novembro de 1968. Fixa as normas de organização e funcionamento do ensino superior e sua articulação com a escola média e dá outras providências. Disponível em: <http://presrepublica.jusbrasil.com.br/ legislacao/109783/lei-554068>. Acesso em: 13 out. 2014.

Presidência da República. Casa Civil. Subchefia para assuntos jurídicos. Decreto-lei no 464, de 11 de fevereiro de 1969. Estabelece normas complementares à Lei no 5.540 , de 28 de novembro de 1968, e dá outras providências. Disponível em: <http://www.planalto. gov.br/ccivil_03/ decreto-lei/1965-1988/Del0464.htm>. Acesso em: 13 out. 2014. 
Jurídicos. Lei no 5.905, de 12 de julho de 1973. Dispõe sobre a criação dos Conselhos Federal e Regionais de Enfermagem e dá outras providências. Disponível em: <http://www.planalto.gov.br/ ccivil_03/ leis/L5905.htm>. Acesso em: 23 out. 2014.

. Presidência da República. Casa Civil. Subchefia para Assuntos Jurídicos. Lei no 6.229, de 17 de julho de 1975. Dispõe sobre a organização do Sistema Nacional de Saúde. Revogada pela Lei no 8.080, de 19 de setembro de 1990. Disponível em: <http://www planalto.gov. br/ccivil_03/leis/L6229.htm>. Acesso em: 16 out. 2014.

. Presidência da República. Casa Civil. Subchefia para Assuntos Jurídicos. Lei no 7.498, de 25 de junho de 1986. Dispõe sobre a Regulamentação do exercício da enfermagem e dá outras providências. D.O.U. de 26 de junho de 1986, Seção I, fls. 9273-9275. Disponível em: <http://presrepublica.jusbrasil. com.br/legislacao/128195/lei-7498-86>. Acesso em: 13 out. 2014.

. Conselho Nacional de Educação/ Câmara de Ensino Superior (CNE/CES). Parecer 1133, 7 ago 2001. Homologado. Despacho do Ministro em 01/10/2001, Diário Oficial da União (DOU), Brasília, 3 de outubro de 2001, Seção IE, p. 131. Disponível em: <http://portal. mec.gov. br/cne/arquivos/pdf/CES04.pdf>. Acesso em: 20 out. 2014.

Conselho Nacional de Educação/Câmara de Ensino Superior (CNE/ CES), Resolução no 3, de 7 de novembro de 2001. Institui Diretrizes Curriculares Nacionais do Curso de Graduação em Enfermagem. Diário Oficial da União, Brasília, 9 de novembro de 2001, seção I. p.37. Disponível em: <http://portal.mec.gov.br/cne/arquivos/ pdf/CES03.pdf>. Acesso em: 13 out. 2014.

Conselho Federal de Enfermagem. Dispõe sobre a Regulamentação do exercício de enfermagem, Diário Oficial da União (D.O.U), de 26/06/86, Seção I, fls. 9273-9275.

COSTA, N. da R. Lutas Urbanas e Controle Sanitário: origens das políticas de saúde no Brasil. 2. ed. Petrópolis: Vozes. Rio de Janeiro: Associação Brasileira de Pós-graduação em Saúde Coletiva, 1986.

CUNHA, L.A. C. R. da. Universidade Temporã. O ensino superior, da Colônia à Era Vargas. 3. ed. São Paulo: Fundação Editora da UNESP (FEU), 1980/2007.

CUNHA, R. L. Valor da Enfermeira nos Serviços de Saúde Pública. 
Rio de Janeiro: (sn), 1923. (Discurso proferido na Sociedade Brasileira de Hygiene).

ENFERMAGEM. ELLU do Brasil. Primeiras escolas de enfermagem no Brasil. Disponível em: <http://www.ellubrasil.com. $\mathrm{br} /$ saude/enfermagem/historia-da-enfermagem/primeiras-escolas-deenfermagem-no-brasil>. Acesso em: 20 out. 2014.

FRIGOTO, G. Educação e crise do capitalismo real. São Paulo: Cortez. 2003

GEOVANINI, T. et. al. História da Enfermagem: Versões e Interpretação. Rio de Janeiro: Revinter, 1995/2002.

MERHY, Emerson. E. A Saúde Pública como Política: um estudo de formuladores de políticos. São Paulo: Hucitec, 1992.

PERES, Maria Angélica de Almeida; ALMEIDA FILHO, Antonio José de; PAIM, Lygia. Historicidade da Enfermagem nos espaços de poder no Brasil. p. 83-94. História da Enfermagem Revista Eletrônica (HERE), v.5, n. 1, jan. - jul, 2014. ISSN 2176-7475. Disponível em: <http://www.abennacional.org.br/centrodememoria/here/ hereinformacoes.htm>. Acesso em: 16 nov. 2014.

PORTAL do Programa de Pós-Graduação em Enfermagem, PPGE, da Universidade Federal do Rio de Janeiro, UNIRIO. História, Diretrizes e Princípios. 2014. Disponível em: <http://www2.unirio.br/unirio/ccbs/ ppgenf/diretrizes>. Acesso em: 22 out. 2014.

RIZZOTTO, M. C. F. História da Enfermagem e sua Relação com a saúde Pública. Goiana: A.B, 1999.

ROCHA, M. E. M. Oliveira da; NUNES, B. M. V. Teixeira. Expansão dos cursos de graduação em Enfermagem: estudo no Piauí. Revista Brasileira de Enfermagem, v. 66, n. 3, Brasília, mai.jun., 2013. Disponível em: <http:/www.scielo.br/scielo.php?pid=S0034$71672013000300014 \&$ script=sci_arttext>. Acesso em: 23 out. 2014.

RODRIGUES, R. A. P. et al. Educação do doutorado em enfermagem no Brasil. Revista Latino-Americana de Enfermagem, v. 16, $\mathrm{n}^{\circ}$ 4, Ribeirão Preto, ago. 2008. ISSN 0104-1169. Disponível em: <http://www.scielo.br/scielo.php?pid=S0104-11692008000400003 \&script=sci_arttext\&tlng=pt>. Acesso em: 23 out. 2014.

ROMANELLI, O. de O. História da Educação no Brasil (1939-1973). 
SINGER, P. A Universidade no Olho do Furacão. Estudos Avançados, Universidade de São Paulo, v. 15, n. 42, 2001.

SOUZA, P. N. P. Como entender e aplicar a nova LDB (Lei No 9394/96). São Paulo: Pioneira,1997.

\title{
THE GRADUATION OF PROFESSIONAL NURSES, INTHE CONTEXTS OF EDUCATIONAL REFORMS AT BRAZIL
}

\begin{abstract}
The present study tried to accomplish the educational trajectory of professional nursing, in period from the inauguration of the first nursing school, at Brazil in 1890, until the end of the XX century. The aim was to carry the discussion about the reality of nursing graduation, based on the regulatory laws, such as the Directives Law's and Bases of National Education, LDBEN, of 1968 and 1996, that determined the forwarding's and the profession institutionalization. The social and economic aspects were relevant, since it characterized political moments that influenced the progress of public policies of professional nursing. The methodology included a survey of works, searching to know the knowledge and author's reflections, based on the legislations to build the trajectory guided by legal conditions. The theoretical approach were backed up with authors, as Luiz Antônio da Cunha, Gaudêncio Frigotto, Telma Geovanini, Emerson Elias Merhy, among others, that addressed issues about nursing and policies undertaken by the government, in order to the correlation between the hygienic/health measures and creation and development of nursing graduation at Brazil. Social Contradictions that permeated the reality of this professional were observed and the determinant economic relevance of policies of reforms and development that characterized the rational and centralizing character of public management in military regime, creating fragmentary of this professional field. The LDBEN of 1996, however, brought to discussion the nursing formation, attending neoliberalism expectations and of market globalization.
\end{abstract}

Keywords: Professional nursing graduation. Education in nursing. Graduation in nursing. Legislation about nursing course. 